Adventist Health

\title{
Final Scientific/Technical Report
}

1. DEPARTMENT OF ENERGY AWARD NO. DE-FG02-04CH11184

\author{
RECIPIENT NAME: Adventist Health
}

PROJECT DIRECTOR: Wynelle J. Huff, PhD (now retired) No new project director named due to conclusion of the award.

No consortium/teaming members

2. No patented material or protected data.

3. Executive Summary: For the past 5 years, Adventist Health has been implementing a clinical information system, titled Project IntelliCare, throughout its 19 hospitals. To successfully do this, a commitment was made to ensure continuous availability of vital patient health information to the local hospitals. This commitment required a centralized data center with sufficient capacity and a backup data center to be used in case of technical software or natural disaster where interruptions could occur. The DOE grant provided financial assistance to purchase equipment to increase the capacity of an existing data center, along with purchase of more sophisticated software for the data center thus providing a reduction in time that information is unavailable to the local hospitals when hardware or software problems occur.

Relative to public good, this translates into increased safety and convenience for the patients we serve because their electronic medical records are current and available a higher percentage of the time.

4. The hardware and software were purchased, installed and are now functional.

5. The only project activities involved were negotiations with vendors, selection of hardware and software, purchase, installation and implementation.

6. No products were developed under the award.

7. No computer modeling was done.

Results

1. Computer room disk capacity was improved such that an online copy of the clinical information could be retrieved in minutes during a disaster rather than requiring a 13 hour recovery from tape. 
2. Two disaster failover tests occurred (12/1/06 - 12/04/06 and 02/09/07 02/11/07). Because of the improved infrastructure, clinical user impact was diminished from eight hours to two hours in both occurrences.

3. Technology implemented allows for monthly validation of disaster recovery environment without impacting clinical users working in production.

8. 